\title{
Comparative analysis of Pseudomonas aeruginosa penicillin-binding protein 7 in the context of its membership in the family of low-molecular-mass PBPs
}

\author{
Jian Song, ${ }^{1} \dagger$ Gary Xie, ${ }^{1}$ Pamela K. Elf, ${ }^{2}$ Kevin D. Young ${ }^{2}$ \\ and Roy A. Jensen ${ }^{1}$
}

1 Department of

Microbiology and Cell

Science, University of

Florida, Gainesville,

FL 32611, USA

2 Department of Microbiology and Immunology, School of Medicine, University of North Dakota, Grand

Forks, ND 58202-9037, USA Author for correspondence: Roy A. Jensen Tel : +1 352392 9677. Fax : +1 3523925922.
e-mail: rjensen@micro.ifas.ufledu

\begin{abstract}
The Pseudomonas aeruginosa pbpG gene encoding penicillin-binding protein 7 , a homologue of the Escherichia coli gene encoding a DD-endopeptidase, was cloned and sequenced. pbpG was located immediately downstream of the phenylalanine hydroxylase (phh) operon. DNA sequencing revealed an open reading frame of 936 bp (starting with a GTG codon) which encodes a protein of $34115 \mathrm{Da}$. $\mathrm{N}$-terminal amino acid sequencing confirmed the presence of a cleavable $\mathbf{N}$-terminal signal peptide of 23 amino acids. Verification that the protein is a penicillin-binding protein was directly demonstrated by labelling with ${ }^{125}$-labelled penicillin $X$. Inactivation of $P$. aeruginosa pbpG by interposon mutagenesis resulted in no obvious phenotypic changes, but when $P$. aeruginosa PbpG was overexpressed in E. coli using a $\mathrm{T7}$ expression system, cell lysis resulted. P. aeruginosa PbpG resembled E. coli PbpG in being associated with the membrane fraction. Two additional members of the PbpG subfamily were identified in the database. P. aeruginosa PbpG shows $63 \%$ identity with $E$, coli penicillin-binding protein 7 (PbpG) and $60 \%$ identity with Vibrio cholerae PbpG, but only $23 \%$ identity with Haemophilus influenzae PbpG. The PbpG subfamily and three other subfamilies constituting the lowmolecular-mass PBP protein family were analysed by multiple alignment of 26 sequences. PbpG exhibited the consensus motifs of other penicillin-binding proteins. Ten anchor residues were identified that are conserved at the family level within the superfamily of serine-active-site penicillin-interacting proteins.
\end{abstract}

Keywords: penicillin-binding proteins, PBP protein family, Pseudomonas aeruginosa

\section{INTRODUCTION}

The murein (peptidoglycan) sacculus is a shapedetermining structure in bacterial cell walls that consists of a complex polymer made up of polysaccharides and peptides (Van Heijenoort, 1996). The murein sacculus is located in the periplasmic space and is essential for maintenance of the integrity of the cytoplasmic membrane. It is intimately related to cell growth and division

†Present address: Department of Microbiology and Immunology, University of Michigan Medical School, Ann Arbor, MI 48109, USA.

Abbreviation: PBP, penicillin-binding protein.

The GenBank accession number for the nucleotide sequence reported in this paper is U62582.
(Waxman \& Strominger, 1983). In endospore-forming bacilli the sacculus also plays a crucial role in the morphogenetic processes of endospore formation and germination (e.g. Murray et al., 1997 and references therein). Elongation of the sacculus during growth is a dynamic process requiring an appropriate balance of formation and hydrolysis of cross-links. Highmolecular-mass penicillin-binding proteins (PBPs) possess a transglycosylase domain, which participates in new cross-linking, and a transpeptidase domain. Lowmolecular-mass PBPs are DD-peptidases of two types. DD-Carboxypeptidases cleave between two D-alanines, thus facilitating the interpeptide cross-linking between an activated terminal D-alanyl moiety of one subunit and meso-diaminopimelate of another subunit. DD- 
Endopeptidases hydrolyse the latter interpeptide crosslinks.

The transpeptidase domain of high-molecular-mass PBPs and the DD-peptidase enzymes (low-molecularmass PBPs) possess a common active-site serine residue associated with a configuration of conserved motifs found in $\beta$-lactamase (Ghuysen, 1991; Ghuysen \& Dive, 1994). PBPs covalently bind penicillin or penicillin derivatives, a property which has facilitated their detection with labelled penicillin following SDS-PAGE. Escherichia coli produces at least 11 (1a, 1b, 1c, 2, 3, 4, 5, 6, 6b, 7 and 8) PBPs (Baquero et al., 1996). Among the low-molecular-mass PBPs, three (PBP5, PBP6, and PBP6b) are DD-carboxypeptidases, whereas PBP4 and PBP7 are DD-endopeptidases.

Although PBP8 of E. coli is also a DD-endopeptidase it has recently been shown to result from processing of PBP7 by the outer-membrane protease OmpT (Henderson et al., 1994). Evidence was obtained suggesting the processing to be an in vitro artifact caused by abnormal contact of these proteins following cell disruption. The gene encoding PBP7 in E. coli, $p b p G$, was recently cloned (Henderson et al., 1995). PBP7 has been reported to be a target for $\beta$-lactam antibiotics that have the unusual property of lysing nongrowing E. coli cells (Tuomanen \& Schwartz, 1987). An increased resistance of $E$. coli to cephaloridine and ceftazidime has been correlated with increased expression of PBP8 (Malouin et al., 1991).

PBPs of Pseudomonas aeruginosa have received relatively little attention, even though $\beta$-lactam antibiotics have been among the few that have proven effective in treating infections caused by this notorious opportunistic pathogen. At least six PBPs in $P$. aeruginosa were described in an early study in which the electrophoretic pattern of PBPs roughly resembled that of $E$. coli (Noguchi et al., 1979). However, the low-molecularmass counterparts of E. coli PBP6 and PBP7 were not definitively detected. The most comprehensive recent work in $P$. aeruginos $a$ has been with the high-molecularmass PBP species, PBP3 (Liao \& Hancock, 1995) and PBP3x (Liao \& Hancock, 1997). These are both homologues of E. coli PBP3. Although they may be catalytically redundant, $P$. aeruginosa $\mathrm{PBP} 3$ and PBP3x probably have specialized roles, since they are differentially regulated (Liao \& Hancock, 1997).

In this paper we present molecular-genetic data supporting the existence of $p b p G$ in the $P$. aeruginosa genome, encoding a homologue of E. coli PBP7. A comparative analysis of four known PBP7 proteins in the context of their membership in the family of lowmolecular-mass PBPs is presented.

\section{METHODS}

Materials. Bacterial strains and plasmids used in this study are described in Table 1. The LB formulation (Sambrook et al., 1989) was used as growth medium for both $E$. coli and $P$. aeruginosa. Pseudomonas isolation agar (Difco) was used for isolating $P$. aeruginosa $p b p G$ knockout mutants. Additions of ampicillin $\left(100 \mu \mathrm{g} \mathrm{ml}^{-1}\right)$, chloramphenicol $\left(40 \mu \mathrm{g} \mathrm{ml}^{-1}\right)$, tetracycline $\left(25 \mu \mathrm{g} \mathrm{ml}^{-1}\right)$ and mercuric chloride $\left(15 \mu \mathrm{g} \mathrm{ml}^{-1}\right)$ were made when required. Ampicillin was never used in growth media when penicillin-binding proteins were to be assayed. Agar was added at $20 \mathrm{~g} \mathrm{l}^{-1}$ for preparation of solid medium. Restriction enzymes, T4 DNA ligase, DNA modifying enzymes (New England Biolabs), and Taq DNA polymerase (Perkin-Elmer) were used as recommended by the suppliers. Other biochemicals were purchased from Sigma. Inorganic chemicals (analytical grade) were from Fisher Scientific.

DNA manipulations and protein assays. Procedures for general DNA manipulation, including plasmid purification, subcloning and restriction analysis were conducted by standard methods (Sambrook et al., 1989). DNA fragments were purified from agarose gels with a Geneclean kit (Bio101). Protein concentrations were estimated by the use of Bradford reagent (Bradford, 1976).

Expression and labelling of PBPs. For overexpression of PbpG in $E$. coli, we used the T7 expression system (Novagen). The coding region of $p b p G$ was placed into a translational fusion vector $(\mathrm{pET} 11 \mathrm{a})$. The coding region was amplified using PCR with the upper 30mer primer 5'-TTCCATATGAGAAACCGTCTCCTGTCACTG-3' (a built-in NdeI site is underlined and the translational start codon is in bold) and the lower 18mer primer (RJ 105) 5'-CTTCGCGACGGATCAGCG-3' (complementary to nucleotides 1504-1521). The PCR fragment was first cloned into the SmaI site of pUC18 and was subsequently excised with $N d e I$ and BamHI. The latter fragment carrying the $p b p G$ gene was then ligated with pET11a digested with $N d e I$ and BamHI, to create the PbpG overexpression plasmid, pJS87. To avoid the toxicity resulting from $\mathrm{PbpG}$ overexpression, the $B g l \mathrm{II}-\mathrm{Bam} \mathrm{HI}$ fragment from pJS87 carrying the $p b p G$ gene was cloned into the low-copynumber plasmid pACYC184, to create pJS89S.

PBP labelling of whole-cell extracts and visualization by SDSPAGE was performed as described previously (Henderson $e t$ al., 1994).

Procedure for osmotic shock. Osmotic shock was performed by a procedure similar to that described by Neu \& Chou (1967). E. coli BL21(DE3)/pJS87 was grown in LB broth supplemented with $100 \mu \mathrm{g}$ ampicillin $\mathrm{ml}^{-1}$ to an $\mathrm{OD}_{600}$ of about 1. Expression of PbpG was then induced by adding $0.4 \mathrm{mM}$ IPTG. Cells were harvested after $2 \mathrm{~h}$ induction by centrifugation at $12000 \mathrm{~g}$ for $15 \mathrm{~min}$ at $4{ }^{\circ} \mathrm{C}$. The cell pellets were washed with $0.85 \% \mathrm{NaCl}$ and resuspended in $20 \%$ sucrose $: 30 \mathrm{mM}$ Tris $/ \mathrm{HCl}(\mathrm{pH} \mathrm{7.3)}$ at room temperature at a ratio of $80 \mathrm{ml}$ sucrose: Tris to $1 \mathrm{~g}$ cells (wet weight). EDTA was added to a concentration of $1 \mathrm{mM}$. After $10 \mathrm{~min}$ of mixing at room temperature, the cells were pelleted by centrifugation at $4{ }^{\circ} \mathrm{C}$. The cell pellets were resuspended in $0.5 \mathrm{mM} \mathrm{MgCl}_{2}$ at $0{ }^{\circ} \mathrm{C}$ and mixed on ice for $10 \mathrm{~min}$. The cells were removed by centrifugation, and the supernatant was collected as the osmotic fraction. The shocked cells were sonicated and the cytoplasmic and membrane fractions were prepared as described below.

Preparation of cytoplasmic and membrane fractions. Cells grown in LB broth until the late-exponential stage were harvested by centrifugation at $12000 \mathrm{~g}$ for $15 \mathrm{~min}$ at $4{ }^{\circ} \mathrm{C}$. The cell pellets were resuspended in $30 \mathrm{mM}$ Tris $/ \mathrm{HCl}(\mathrm{pH} \mathrm{7 \cdot 3})$, and sonicated for $2 \times 30 \mathrm{~s}$ with a Labline sonicator. Cell debris and unbroken cells were removed by centrifugation at $3000 \mathrm{~g}$ for $10 \mathrm{~min}$ at $4{ }^{\circ} \mathrm{C}$. The supernatant was centrifuged at $150000 \mathrm{~g}$ for $65 \mathrm{~min}$ at $4{ }^{\circ} \mathrm{C}$. The pelleted membranes were washed and resuspended in the same buffer. The supernatant is referred to as the cytoplasmic fraction. 
Table 1. Strains and plasmids used in this study

\begin{tabular}{|c|c|c|}
\hline $\begin{array}{l}\text { Strain or } \\
\text { plasmid }\end{array}$ & Relevant genotype or description & Source or reference \\
\hline \multicolumn{3}{|l|}{ E. coli } \\
\hline BL21(DE3) & $\begin{array}{l}\mathrm{F}^{-} \text {ompT } h s d S_{B}\left(\mathrm{r}_{\mathrm{B}}{ }^{-} \mathrm{m}_{\mathrm{B}}{ }^{-}\right) \text {gal } d c m \text {; with } \\
\mathrm{DE} 3, \text { a } \lambda \text { prophage carrying the } \mathrm{T}_{7} \text { RNA } \\
\text { polymerase gene }\end{array}$ & Novagen \\
\hline CS109 & $\mathrm{W} 1485, \lambda^{-} \mathrm{F}^{-}$thi $g \ln V(s u p E)$ rph rpoS & Henderson et al. (1997) \\
\hline CS9-19 & $p b p G:: r e s$ in CS109 background & $\begin{array}{l}\text { S. A. Denome and others, } \\
\text { unpublished }\end{array}$ \\
\hline DH5 $\alpha$ & $\begin{array}{l}\mathrm{F}^{-} e 14^{-}(m c r A) \text { bsdR514 }\left(\mathrm{r}_{\mathrm{k}}^{-} \mathrm{m}_{\mathrm{k}}^{+}\right) \text {recA1 } \\
\text { endA1 gyrA96 thi-1 relA1 supE44 }\end{array}$ & Gibco-BRL \\
\hline$S 17-1$ & $\begin{array}{l}{[\mathrm{RP} 4-2(\mathrm{Tc}:: \mathrm{Mu})(\mathrm{Km}:: \mathrm{Tn} 7) \text { Tra }(\mathrm{IncP})]} \\
\quad \text { pro hsdR recA } \mathrm{Tp}^{\mathrm{r}} \mathrm{Sm}^{\mathrm{r}}\end{array}$ & Simon et al. (1983) \\
\hline \multicolumn{3}{|c|}{ P. aeruginosa } \\
\hline PAO-1 & Prototroph & $\begin{array}{l}\text { D. H. Calhoun, City College, } \\
\text { New York }\end{array}$ \\
\hline JS105 & $\mathrm{PAO}-1, \Delta p b p G, \mathrm{Hg}^{\mathrm{r}}$ & This study \\
\hline \multicolumn{3}{|l|}{ Plasmids } \\
\hline pACYC184 & $\mathrm{Cm}^{\mathrm{r}} \mathrm{Tc}^{\mathrm{r}}$; low-copy-number cloning vector & Chang \& Cohen (1978) \\
\hline pET11a & T7lac promoter, lacI $I^{+} \mathrm{Amp}^{\mathrm{r}}$ & Novagen \\
\hline pJS6 & $\begin{array}{l}\text { SphI-HindIII fragment carrying } p b p G \\
\text { cloned into pUC18 }\end{array}$ & This study \\
\hline pJS87 & $\begin{array}{l}\text { PbpG overexpression plasmid, PbpG- } \\
\text { coding region fused with } \mathrm{T} 7 \\
\text { translational initiation signal at NdeI site } \\
\text { of pET11a }\end{array}$ & This study \\
\hline pJS89 & $\begin{array}{l}\text { XbaI-BamHI fragment carrying } p b p G \\
\text { from pJS87 cloned into pUC19 }\end{array}$ & This study \\
\hline pJS89S & $\begin{array}{l}\text { Bglll-BamHI fragment carrying } p b p G \\
\text { from pJS87 cloned into pACYC184 }\end{array}$ & This study \\
\hline pJZ9 & 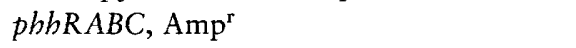 & Zhao et al. (1994) \\
\hline pUC18 & Amp $^{r}$; high-copy-number cloning vector & Yanisch-Perron et al. (1985) \\
\hline pUC19 & $\mathrm{Amp}^{\mathrm{r}}$; high-copy-number cloning vector & Yanisch-Perron et al. (1985) \\
\hline pUFR004 & ColE1, $\mathrm{Cm}^{\mathrm{r}} \mathrm{Mob}^{+} \operatorname{mobP} \mathrm{lacZa} a^{+}$ & Defeyter et al. (1990) \\
\hline
\end{tabular}

Inactivation of pbpG in P. aeruginosa. $p b p G$ was inactivated by marker interruption (Kamoun et al., 1992) as described by Song \& Jensen (1996). To generate the truncated ' $p b p G$ ' fragment (614 bp), the upper $26 \mathrm{mer}$ primer 5'-GGGCTGCCGCTGCAACAGGAGCTGGC-3' (nucleotides 661686 ), and the lower 26mer primer 5'-GTGAAGCCGGTCTTGGTCAACTGGAT-3' (complementary to nucleotides 1249-1274) were used. Interruption of the $p b p G$ gene in a $P$. aeruginosa $\mathrm{Hg}^{\mathrm{r}}$ isolate was confirmed by Southern hybridization.

Nucleotide sequencing and data analysis. Plasmid pJS6 was sequenced by the DNA Sequencing Core Lab of the Interdisciplinary Center for Biotechnology Research (ICBR) of the University of Florida. Primers were made by the DNA Synthesis Core Lab of the ICBR. The nucleotide sequence and the deduced amino acid sequence were analysed by using the Genetics Computer Group (University of Wisconsin) software packages. Amino acid sequences were analysed for $\mathrm{N}$-terminal signal sequences and transmembrane domains using PSORT (http://psort.nibb.ac.jp) (Nakai \& Kanehisa, 1991).

$\mathrm{N}$-terminal amino acid sequencing. Samples for $\mathrm{N}$-terminal amino acid sequencing were processed with an Applied
Biosystems model 407A protein sequencer with an on-line $120 \mathrm{~A}$ phenylthiohydantoin analyser in the Protein Core Facility of the ICBR at the University of Florida.

\section{RESULTS}

\section{Cloning and sequencing of $p b p G$}

The original clone isolated by Zhao et al. (1994) is shown in Fig. 1. Both upstream and downstream flanking regions of the $p h b A B C$ operon were originally regarded as candidate locations for regulatory genes because presence or absence of these flanking regions in subclone derivatives influenced the expression levels of genes in the $p h b$ operon. Indeed, the upstream region proved to house a positively acting regulatory gene, phbR (Song \& Jensen, 1996). Elevated expression of $p b p G$ in the downstream region was found to be deleterious to growth, causing cells to be prone to lysis. Hence, the negative effect of $p b p G$ on expression of $p h b$ operon genes was indirect. Fig. 1 shows the subclone construct (pJS6) used for nucleotide sequencing. 


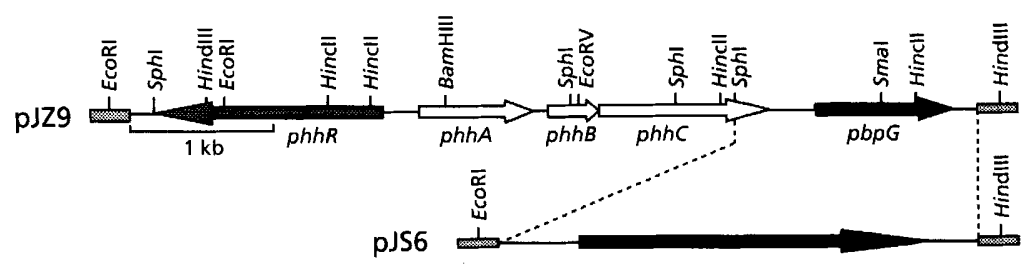

Fig. 1. Physical map of $P$. aeruginosa $p b p G$ (solid arrow), and the upstream flanking region containing the phhR regulatory gene (shaded arrow) and the structural gene members (open arrows) of the phh operon. Positions of restriction sites in the cloned DNA and in the pUC polylinker region (shaded bars) are shown at the top. pJZ9 is the original clone isolated, and pjS6 is the subclone used for nucleotide sequencing.

$p b p G$ utilizes a GTG start codon. The possible use of ATG start codons further upstream was discounted because of the presence of tandem stop codons (TAG TGA). An AGTGAG hexamer provides a putative ribosome-binding site with suitable spacing (8 nucleotides). The 134 nucleotide region between the terminator following the $p h b$ operon and the ribosome-binding site ahead of $p b p G$ was examined in an attempt to identify a likely promoter, but possible promoters corresponding to consensus sequences for $\sigma^{70}, \sigma^{54}$ or $\sigma^{\mathrm{E}}$ were all too marginal to merit speculation. The deduced mature $\mathrm{PbpG}$ protein is positively charged and exhibits a calculated isoelectric point of $10 \cdot 37$. It possesses only a single cysteine residue.

Downstream of $p b p G$ is a convergently transcribed gene (yaeJ) of unknown function. However, it is a homologue ( $52 \%$ identity) of a $15.6 \mathrm{kDa}$ protein in E. coli which is transcribed immediately ahead of $n p l E(c u t F)$, both apparently belonging to a common operon (Gupta et al., $1995)$. Another homologue ( $68 \%$ identity) is a $15 \cdot 2 \mathrm{kDa}$ protein from Pseudomonas putida, which is transcribed convergently with $p c a J$, and encodes a subunit of $\beta$ ketoadipate:succinyl-Coenzyme A transferase (Parales \& Harwood, 1992). The truncated C-terminal portion of $P$. aeruginosa $\mathrm{YaeJ}$ has a high content of basic amino acids and only few acidic amino acids $(8 \mathrm{~K}, 8 \mathrm{R}, 2 \mathrm{D}, 0 \mathrm{E})$. Of the 16 basic residues in P. aeruginosa YaeJ, 9 are identical conserved residues in all three YaeJ homologues. The extreme positive charge of these proteins is consistent with DNA- or RNA-binding properties and a regulatory function. Since yae is transcribed convergently with $p b p G$ in $P$. aeruginosa, the gene organization in this region differs from that of the closely related P. putida. Only 22 bp separate the stop codons of the convergently transcribed $p b p G$ and yaeJ genes. The mechanism used for transcript termination in this region would be of interest. Several potential stem-loop structures span this intergenic region. YaeJ possesses two regions that have been reported to show significant homology to peptide chain release factors in prokaryotes (Gupta et al., 1995).

\section{Subcellular location of PbpG}

PpbG was overexpressed in E. coli BL21(DE3)/pJS87 using the T7 expression system (Novagen). PpbG was readily visible as a prominent band of the expected size following SDS-PAGE of samples from whole-cell lysates

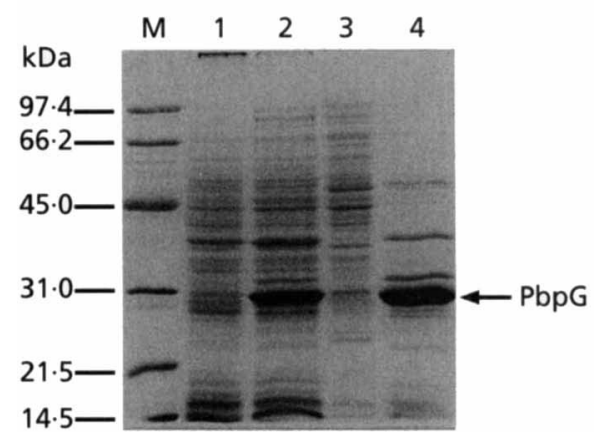

Fig. 2. Overexpression and subcellular location of $P$. aeruginosa PbpG in E. coli BL21(DE3) using the T7 expression system. Proteins in whole-cell lysates or subcellular fractions were separated on SDS-12\% PAGE gels. Lane $M$, molecular-mass standards; Lanes: 1, whole-cell lysate BL21(DE3)/pJS87 in the absence of IPTG induction; 2, whole-cell lysate of BL21(DE3)/pJS87 following induction with $0.4 \mathrm{mM}$ IPTG; 3 , cytoplasmic fraction of BL21(DE3)/pJS87 prepared from an IPTG. induced culture; 4, membrane fraction of $B L 21(D E 3) / p J S 87$ prepared from an IPTG-induced culture.

(Fig. 2, lane 2). Osmotic shock experiments were done using cyclohexadienyl dehydratase as a positive control for periplasm localization (Zhao et al., 1993). It was qualitatively apparent from the SDS-PAGE analysis that little or no PbpG was present in the periplasmic fraction.

An IPTG-induced culture strongly expressing PbpG in whole-cell lysates (Fig. 2, lane 2) was fractionated into a cytoplasmic fraction and a membrane fraction (as described in Methods). Fig. 2 shows that most or all PbpG was located in the membrane fraction (lane 4), and not in the cytoplasmic fraction (lane 3).

PbpG protein overproduced in E. coli BL21(DE3)/pJS87 was first isolated in the membrane fraction and then separated from other membrane proteins by SDS-PAGE. The gel was then blotted onto a PVDF membrane (Bio$\mathrm{Rad}$ ) and stained with Coomassie brilliant blue R-250 (Sigma). The band corresponding to PbpG was excised from the membrane and used for $\mathrm{N}$-terminal amino acid sequencing. The $\mathrm{N}$-terminal amino acid sequence obtained (SPPPKA) confirmed the existence of a signal peptide. The 23-residue signal peptide deduced from the nucleotide sequence (MRNRLLSLVTLFLSLSVATAVSA) fulfils the three standard criteria for cleavable signal peptides (Nakai \& Kanehisa, 1991). 


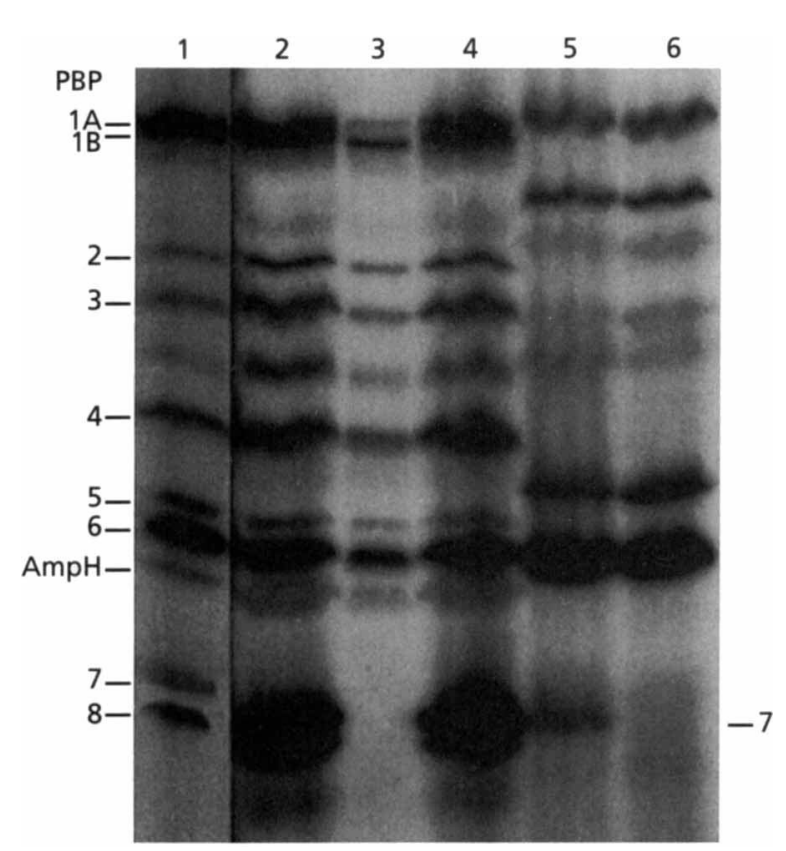

Fig. 3. Identification of PBP7 in E. coli and P. aeruginosa. PBPs were labelled with ${ }^{125} \mathrm{l}$-penicillin $X$ as described in Methods. Lane 1, wild-type E. coli CS109; lane 2, E. coli CS109/pJS89S expressing cloned $P$. aeruginosa $\mathrm{Pbp} 7$; lane 3, E. coli CS9-19 (mutant lacking Pbp7/8); lane 4, E. coli CS9-19/pJS89S; lane 5, $P$. aeruginosa PAO-1 (wild-type); lane $6, P$. aeruginosa JS105 (mutant lacking Pbp7/8). E. coli PBPs are identified on the left margin. AmpH marks the position of a newly described $\beta$ lactamase (Henderson et al., 1997).

Direct confirmation that $P$. aeruginosa $P b p G$ is a penicillin-binding protein on the classical criterion is shown in Fig. 3. Lane 3 shows the absence of E. coli $\mathrm{Pbp} 7 / 8$ in a pbpG mutant. Overexpression of $P$. aeruginosa $p b p G$ in this mutant background is apparent from the appearance of high protein levels in the general electrophoretic positions of E. coli Ppb7/8. Bands corresponding to at least eight PBP species are evident in lysates prepared from wild-type $P$. aeruginosa PAO-1 (lane 5). The identity of the bottom band as PpbG was confirmed by results obtained with strain JS105, which carries an interposon mutation within $p b p G$ (lane 6).

The $P$. aeruginosa PbpG band in lane 5 of fig. 3 appears to have a lower molecular mass than the E. coli Pbp8 species. This would be consistent with cleavage of $37 \mathrm{C}$ terminal amino acids by the OmpT protease at the RR residues marked in Fig. 4. On the other hand, overexpression in the BL21(DE3) system (which lacks a functional OmpT) yielded a protein of the expected size (Fig. 2).

\section{Physiological effects of perturbation of PbpG levels}

As noted earlier, the original clone pJZ9 (Fig. 1) resulted in a tendency for the host cells to lyse. When PbpG was overproduced in E. coli BL21(DE3)/pJS87, obvious cell lysis began $2 \mathrm{~h}$ after IPTG induction, with progressively more marked lysis thereafter. On the other hand, when $p b p G$ was inactivated in a $P$. aeruginosa knockout mutant, no phenotypic changes were observed in growth rate, survival or colony morphology on minimal saltsglucose medium or an enriched medium (LB).

\section{DISCUSSION}

\section{The PbpG subfamily}

$P$. aeruginosa $\mathrm{PbpG}$ appears to resemble E. coli $\mathrm{PbpG}$, its nearest known homologue. We have located two other $p b p G$ sequences in the database. Of these, Vibrio cholerae $p b p G$ is quite similar to the foregoing two, whereas $H$. influenzae $p b p G$ is the most divergent of the four. E. coli $\mathrm{PbpG}$ is membrane associated, but has been shown not to be an integral membrane protein (Romeis \& Höltje, 1994). It can be dissociated from membranes in high salt and released by osmotic shock. P. aeruginosa PbpG is also membrane associated. Although PSORT analysis indicates a potential membrane-spanning region between residues 60 and 77, this is highly unlikely, since this region encompasses an established active-site motif (SxxK) for the PBP family. E. coli PbpG possesses a KK target for OmpT (residues 296-297) which generates Pbp8 as a processing artifact (Henderson et al., 1994). P. aeruginosa $\mathrm{PbpG}$ possesses an RR target for OmpT (residues 273-274) which also appears to generate a carboxy-cleaved gene product. As is the case in $E$. coli (Henderson et al., 1995) inactivation of $p b p G$ produces no obvious phenotype under ordinary conditions of laboratory culture. However, overexpression of $P$. aeruginosa $\mathrm{PbpG}$ in $E$. coli was not tolerated, and dramatic cell lysis occurred.

As illustrated by the dendrogram in Fig. 4, the PbpG subfamily is closer to the DacA-F subfamily. However, the catalytic specificity of the PbpG subfamily is more similar to that of the DacB subfamily. Therefore, we compared the sequences of the latter two subfamilies for regions that might be conserved. Only two regions were found. One region provides the motif S/TGLS (corresponding to residues $163-166$ of $P$. aeruginosa $\mathrm{PbpG}$ ). The other motif is $\mathrm{SxNxxA}$ (corresponding to residues 121-126 of $P$. aeruginosa $\mathrm{PbpG}$ ).

\section{The low-molecular-mass PBP family}

Multiple homologues of the low-molecular-mass PBPs are often present in a single organism. Such protein families are called paralogues and presumably arose from a series of gene duplications. Sequencing of the entire genome of a growing number of prokaryotes is complete or nearly complete, thus allowing recognition of the total complement of PBP paralogues in such organisms. Escherichia coli and Bacillus subtilis represent widely divergent phylogenetic groupings in which PBPs have been intensively studied. Each exhibits three paralogues in what we will term the DacA-F cluster, although the $B$. subtilis paralogues are much more divergent. Each organism also exhibits a paralogue 


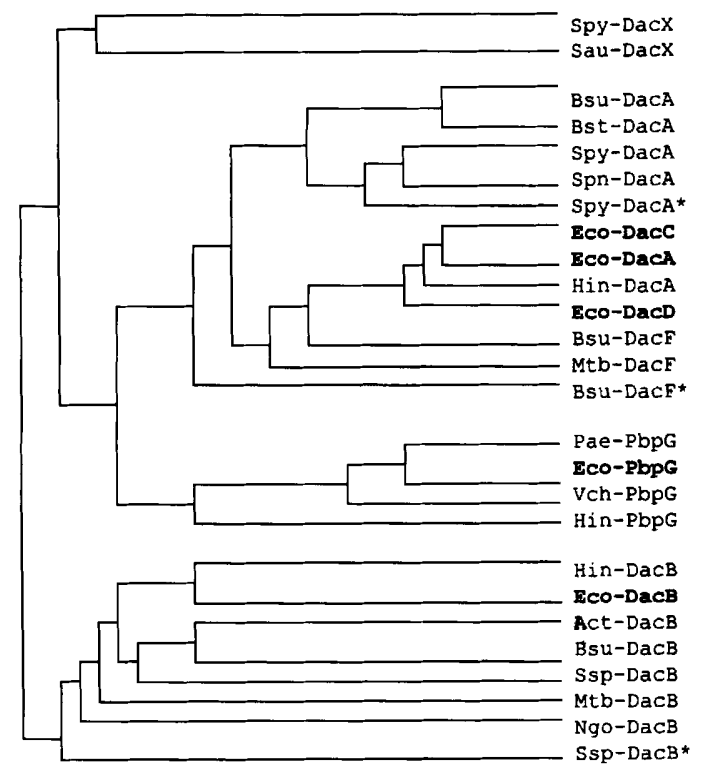

Contig261 JC4555 (PbpD)

P08750 (DacA) Q05523(DaCA) $\mathrm{X} 89237$ (DacA) X99400 (DacA) Contig289 P08506 (DacC) P0 4287 (DacA) P44466 (DacA) P33013 (PhSE) P38422 (DacF) 274024 (MTCY274,43) B42274(Pbp5*)

U62582 (PbpG) P33364 (PbP7) GVCCY59R U32720 (Pbp7)

P45161 (Pbp4) $\mathrm{P} 24228$ ( $\mathrm{PbP} 4$ ) P39045 (DaC) P39844 (Pbp) $\mathrm{D} 64002$ ( $\mathrm{Pbp} 4$ ) 295436 (MTCY) Contig303 D90912 (s111369)
$* * *$

$24 \downarrow \quad 48$ EPTSAVNVSO TGQLLY.... DIPRD D DTKWNPASOS KMFTLYYILFE $\begin{array}{ccc}24 \downarrow & 48 & \text { EPTSAVNVSO TGQLLYYYNI DTKWNPASOYT KLMTMYLTLE } \\ 31 \downarrow & 40 & \text { ASAAIMIEAS SGKILYSKNA DKRLPIASMT KMMTEYLLLE }\end{array}$ $30 \downarrow 39$ ADAAILVDAQ TGRILYEKNI DTVLGIASMT KMMTEYLLLD

$21 \downarrow 29$ AKHAIAVDLE SGKVLYEKDA KEVVPVASVS KLLTTYLVYK

$20 \downarrow 29$ AKHAIAVEAN TGKILYEKDA TQPVEIASIT KLITVYLVYE

$55 \downarrow 62$ AEHAIVVEAD SGRVIYEKDA KTPDAIASLT KLVTAYLVLD

$27 \downarrow 39$ ARAWILMDYA SGKVLAEGNA DEKLDPASLT KIMTSYVVGQ

$29 \downarrow 46$ AESYILIDYN SGKVLAEQNA DVRRDPASLT KMMTSYVIGQ

$18 \downarrow 38$ AQTYVLMDYN SGAILTALNP DQRQYPASLT KMMTSYVVGV

$21 \downarrow 38$ AGSWVLMDYT TGQILTAGNE HQQRNPASLT KLMTGYVVDR

$23 \downarrow 37$ AKSAVLIERD TGKVLYNKNS NERLAPASMT KIMTMLLIME

$22 \downarrow 42$ AQTWIVADLD SGQVLAGRDQ NVAHPPASTI KVLLALV...

$27 \downarrow 33$ AKSAIIIDGA SGRVLYAKDE HQKRRIASIT KIMTAVL...

$23 \downarrow \quad 39$ SGSALVTDON TGKVIYSRNP DLVVPIASIT KCMMAMVVID

$28 \downarrow \quad 43$ SGSAMIVDLN TNKVIYSNHP DLVRPIASIS KLMTAMVVID $25 \downarrow \quad 47$ ANSALVIDLK TNEIIYSNNP DAVKPIASVT KLMTAIVTID $18 \downarrow \begin{array}{lll}19 & \text {.QSYVVYDFT HNRVLESHAS DSIQPIASVT KLMTAANVFLE }\end{array}$

$26 \downarrow 42$ NVGFIAKNIN QNQI IADYNG STFMLSASTQ KVFTAVAAKL $20 \downarrow 35$ NLALMVOKVG ASAPAIDYHS QQMALPASTQ KVITALAALI 49\71 VSGVVVDTTA TGEELYSRDG GEQLLPASNM KLFTAAAALE $29 \downarrow 54$ MAGITVRSAE TGAVLYEHSG DTRMRPASSL KLLTAAAALS $38 \downarrow 63$ OWGIATOPLT DSQPTYOYOA DRFFIPASNO KLITTAMALO $\begin{array}{llll}38 & 63 & \text { QWGIAIQPLT DSQPIYQYQA DRFFIPASNQ KEITIAMAL } \\ 27 & 87 & \text { KLAGRITDAL TGQELORLD DVPLVPASTN KILTAAAALL } \\ 6 & 7 & \end{array}$ $\begin{array}{lllll}27 \downarrow & 87 & \text { KLAGRITDAL TGQELWQRLD DVPLVPASTN KILTAAAALL } & 126 \\ 60 \downarrow & 70 & \text { EIAYYVQELD SGKVIIDHRA GIPVNPASTM KLVTAFAAFK } & 109\end{array}$ $41 \downarrow 65$ RQGIWIQS.. EWAYLGYNQG ESAFPAASLT KIATSVAAID 102

* *

SPY-DaCX ELAKGKITMD TTITATPTDQ AIAN..IYEI SNNNIVAGVA YPIRDLITMT Sau-DacX

Bsu-DacA Bst-DacA Spy-DacA Spn-DacA Spy-DacA Eco-DacC Eco-DacA Hin-DacA ECO-DaCD Bsu-DacF Mtb-DacF Bsu-DacF

Pae-PbpG Eco-PbpG Vch-PbPG Hin-PbpG

Hin-DacB ECo-DaCB Act-DacB Bsu-DacB Ssp-DacB Mtb-DacB

Ngo-DacB

Ssp-DacB*

Spy-DacX Sau-DacX

Bsu-DacA Bst-DacA Spy-DacA Spn-DacA Spy-DacA Eco-DacC ECo-DacA ECo-DacD Bsu-DacF Bsu-DacE Mtb-DacF

Pae-PbpG Eco-PbpG Vch-PbpG Hin-PbpG

Hin-DacB ECO-DacB ACt-DaCB Bsu-DacB Ssp-DacB Mtb-DacB Ngo-DacB AVNKGQLSLD DTVTMTNKEY IMST. . LPEL SNTKLYPGQV WTIADLLQIT AIDQGKVKWD QTYTPDDYVY EISQD. .NSL SNVPLRKDGK YTVKELYQAT AIKAKRVKWD OMYTPSDYVY RLSOD. RAL, SNVPLRKDGK YTVRELYEAM EVSKGKLNWD SPVTISNYPY ELTTN. . YTI SNVPLDKR.K YTVKELLSAL ALENGSITLS TPVDISDYPY QLTTN. . SEA SNIPMEAR.N YTVEELILAT KVKSGQLQLS DQVNLSDYAF ELTKD. .RSL SNVPFDKK.T YSVQDLLTAT ALKADKIKLT DMVTVGKDAW ATGNPALRGS SVMFLKPGDQ VSVADLNKGV AMKAGKFKET DLVTIGNDAW ATGNPVEKGS SLMFLKPGMQ VPVSQLIRGI ALKQGKIHNT DMVTIGESAW GRN....FPDS SKMELDLNTQ VSVADLNRGV AIDSHRITPD DIVTVGRDAW AKDNPVFVGS SLMFLREGDR VSVRDLSRGL AIDSHRITPD DIVTVGRDAW AKDNPVFVGS SLMFLKEGDR VSVRDLSRGL
ALDKGKIKMS DKV ......R TSEHAASMGG SQIFLEPGEE MTVKEMLKGI ALDKGKIKMS DKV ....... R TSEHAASMGG SQIFLEPGEE MTVKEMLKGI
ALDELDLNST VVADV .......... ADTQAEC NCVGVKPGRS YTARQI.DGI ALDELDLNST VVADV..... $\ldots$. ADTQAEC NCVGVKPGRS YTARQLIDGL
AIESGKMDQT VTVSA..... S....KLPLD EVLPI..... AISETSEMRG VFSRVRVGSQ ISRRDMLLLA A.... RLPLD EKLKV...... DISQTPEMKG VYSRVRLNSE ISRKDMLLLA A.... KLPMD AKLPI..... TIKDAKEMKG VHSRVKIGSE ISRKDMLLLT N.... NKNPN CRIAI..... TKEDTDRIKG TGTKLPKNIP ISCNELLKAM ALDDGIEENG KVL...........LPQKPQ QGQLLAKHLS KPLPDLLKKM QLGPGITWSG TLL........... RQTQVNE PGTVVASKQS APLHDLLKIM VLGAGVTVKG DVG......... LGGVPADWQ DAEVLADHTS AELSEILVPE VLGEGITVKG DIK......... . TGEAPS... SSDVLLSHRS MPLSKIFVPE ELGPGISVST SIV........ SANTKAI. . ARAPLLALTS PPLWTLIKTV TLDRE $\ldots \ldots \ldots \ldots \ldots \ldots \ldots \ldots \ldots$. ARQLAVVQS APLIQRLSQM

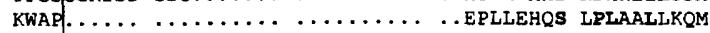

FSNASGAAAQ AFQGYYNPTK YDLSASNITT ARDLSKLLYA FLKKYPEIIS FNIPTGAENS RLRT. FAPTK YKDQERTVTT ARDYAILDLH VIKETPKILD FVNATGLENK DLHGHQPEGT .SVNEESEVS AKDMAVLADH LITDYPEILE FVNATGLSNK DLKGFHPEGT . STNEENVMS ARAMAMLAYR LLKDHPEVLK VVNSTGLTNH FLGANTYPNT .EPDDENCFC ATDIAVIARH LLLEFPEVLK VVNTTGLNNE TLGDNIYPGS . KKDEENKLS AYDVAIVARN LIKKYPQVLE ILNASGLPNE VLKDHRYPGS . ALEEENMLS AQDVAIVTMH LLEDFPEILE FQTVHELD. . $\ldots \ldots \ldots \ldots \ldots$. APGQFST ARDMALLGKA LIHDVPEEYA FQTVHGLD. . . . . . . . . ADGQYSS ARDMALIGQA LIRDVRNEYS ETTPHGID.. ........... DPNQYSS ARDMAIIGAH IIRDLPEEYK FETVHGLD. . $\ldots \ldots \ldots \ldots \ldots \ldots$. $\ldots$ APGQHSS AYDLAVLSRA IIHGEPEFYH FETVHGLD. $\ldots \ldots \ldots \ldots \ldots \ldots \ldots$ APGQHSS AYDLAVLSRA IIHGEPEFYH

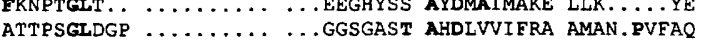
FQNPHGLDDH $\cdots \cdots \cdots \cdots \cdots \cdots$ EN. HYST AYDMAILTKY AIEA.ERLSK YVEPTGLSLH $\ldots \ldots \ldots \ldots \ldots \ldots$ NVST ARDLTRLLVA ..... SRQYP FVEPTGLSVH $\ldots \ldots \ldots \ldots \ldots \ldots$ NVST ARDLTKLLIA $\ldots \ldots$ SKQYP FVEPTELSAK $\ldots \ldots \ldots \ldots \ldots \ldots$ NVST ARDLVVLLLKA $\ldots \ldots$ SKKYP FHDSSGLSSY $\cdots \cdots \cdots \cdots \cdots \cdots$ NISS PMDLVKLAKY $\ldots$. LADGSGLS. $\ldots \ldots \ldots \ldots, \ldots$ RHNLVA PKTMLSVLEY IAKNEDKLH. . RHNLIA PATMMQVLQY IAQHDNELN. LNDGSGLS... . . . . . . . . RGNLVT ADTVVDLLGQ AGSAPWAQT. $\begin{array}{lllll}\text { LRDGSGIS. } & \ldots \ldots \ldots \ldots & \ldots \ldots & \ldots & \ldots \\ \text { LRDGAVS SDQLSQLLYD IQDQSWFSA. }\end{array}$ LVDSSGLS $\ldots \ldots \ldots \ldots \ldots \ldots \ldots$ LDNRLT ARTLDATMQA AAGPDQPALR LDNRSGLS. $\ldots \ldots \ldots \ldots \ldots \ldots \ldots$ TKTVS ARINAPIWKR LISARLHKIS

Fig. 4. For legend see facing page.
AVPSSNAATV MIANYLSNN. ....... DA SAFIDRVNAT AKQLETTNTH 115 SNSSYMAAAL ILAKKVSKN. ........T SDEVDLLMNNK AKAIGMKNTH 07 ET KFVEKMNAK AKELGLTDYK 167 $\begin{array}{llll}\text { AIYSANGATV AIAEIIAGS. } & \ldots \ldots \ldots \text { EK . NFVKMMNDK AKELGLKDYK } & 166 \\ \text { VVNNANSPAI ALAEKIGGT. } & \ldots \ldots \ldots \text { EP . KFVDKMKKQ LRQWGISDAK } & 155\end{array}$

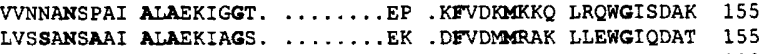
LVASSNSAAI ALAEKVAGS. . . . . . . . EL . HEVNQMREQ LSHWGITSGK 188 IIQSGNDACI ALADYVAGS. $\ldots \ldots \ldots$ QE . SFIGLMNGY AKKLGLTNTT 168 NLQSGNDACV AMADFAAGS. . . . . . Q . AEVGLMNSY VNALGLKNTH 175 IVVSGNDATV ALAEHISGN. ........VP .NFVETMNKY VQQFGLKNTN 164 IVDSGNDACV ALADYIAGG. $\ldots \ldots \ldots$. QR . OFVEMMNNY AEKLHLKDTH 167 AIASGNDASV AMAEFISGS. $\ldots \ldots \ldots$ EE . EFVKKMNKK AKELGLKNTS 160

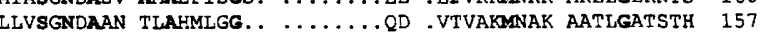
MLRSGNDAAV AIAEHVGGS. $\ldots \ldots \ldots$ LD . GEVYMYNQK AEQLGMKNTR 151 IMSSENRAAA SIAQNYPGG. . . . . KN .AFVKAMANAK AHALGMKNTR 15 LMSSENRAAA SLAHHYPGG. . . . . . YK . AFIKAMANAK AKSIGANNTR 163 LMSSEIRAAA SLAHHYPGG. ........ YK . AFIKAMANAK AKALERKNTR 167

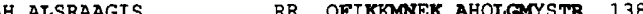

SLFRAVAFNY YKRPASFOLG TLAVKSILOK Q.GIRFGNSI 355 LKKSDMIAD TVFRMIGHAR FNVPGTWRAG SDAVRQILRQ QAGVDIGNTI 352 MKESNNGHAE MLVKSIGQET .AGAGTWDAG LVGVEEAL.S GLGVDTAGLV 391 MRLSNNGHAE VLVKEMGKVK .KGEGSWEKG LEVLNSTL.P EFGVDSKSLV 372 NQDSNSLYAE ALLNAIQPPS .QATD..... ....WQSYV.E RLGLATTTVR 361 MNASDNVMAE CIGREVAVA. INRPQSFSGA VDAVTSRLNT AH.IDTAGAA 339 NNRSDNLIAR SVFLKLRGER KLPAVSQAAS AVRRKLAVS. . .GIHVADLV 382 NIYSNNDMAE MLAQAIGGAA IVAQTTSRLG ............AIPAAEIQ 285 **

FTNKSVVHTM VGTPYEEEFH TYNHSLPD., NQFGMKGVDG IKTGSSPSAA 213 FTKQ.....L APTTHAVTYY TFNFSLEG. . AKMSLPGTDG LKTGSSDTAN 267 TSSIAKTKFR EGTDDEMDMP NWNFMLKGLV SEYKKATVDG LKTGSTDSAG 266 TASIPHKVFR EGTKDEIKMD NWNWMLPGLV YGY..EGVDG LKTGYTEFAG 263 LSSKSSTIFA GQT.....IY SYNYMLKGMP CY..REGVDG LIVGYSKKAG 247 ITKKPSSTEA GMT...... IT STNYMLEGMP AY..RGGFDG LKTGTTDKAG 247 ITKQTEVDFA GNS......IK SFNQLLPGMA KG.. RAGVDG LKTGTTDLAG 280 IHKEKEFTFN KIRQPNRNRL LWSSNLN... . ......EDG MKTGTTAGAG 243 IYKEKEFTFN GIRQLNRNGL LWDNSLN... . ......VDG IKTGHTDKAG 250 IYSEKNFTEN KIKQANRNGL LWDKTIN... . ....... VDG MKTGHTSQAG 239 MYSEKSLTWN GITQQNRNGL LWDKTMN... .......VDG LKTGHTSGAG 242 SITKFTGTYE DYLRENTDKK FWLVNTNRLI KFY..PGVDG VKTGYTGEAK 238 ITAEPSAMEP SDNGEQLIVN QDELLQR.YP .......GAIG GKTGYTNAAR 238 DFRHKN... IO AETMESVWKN KNKLLTMLYP ........YSTG GKTGYTKLAK 228 LLSQWSTTPE KTVAFRHPNY TLGFRNTNHI INNKTWNIQL TKTGFTNEAG 238 LIGQLSTTRE DMATFSNPTY TLPFRNTNHL VYRDNWNIQL TKTGFTNAAG 242 LIGKLSATDK KTVTFSKPRY TLDFRNTNRI VHNDNWKIDL TKTGFTNAAG 246 DIKRLSNLSA .. TYIQAGKQ KLYIRNTNKA VRDEIFDAAV NKTGYIQESG 215 FISMLPL.. AG....... YDG SLOYR. . AGL HOAGVDGKVS AKTG.SLQGV 424 WSASLPV. . AGESDPFVGG TLANR.... M RGTAAEGVVE AKTG. TMSGV 466 YLNSLPV.. A AGNPDRMVGG TLRNR.....M KGTPAQGKVR AKTG.SLSTV 447 YQQSLAV.. AGR...... SG TLERS..... F ADTPLVGKMR GKTG.TLTGV 431 PLLDLLPI.. AGG........SG TLGERFLDAA TDQGPAGWLR AKTG.SLTAI 415 GIDDIFPV. . MGRDRR...G TLEWR. .... ... SMPQGLT IKTG.TLNTV 355 LMETFPI. . AG. . . . . VDG TISGR. .GGL ISPPLVKNVI AKTG.SLKGV 427 STRC..PI.. AGT....... DG TLRNRF.... .. KQSGGLLR IKTG.TLNNV 450 175

.

.




\begin{tabular}{|c|c|c|c|c|c|c|c|c|c|c|c|}
\hline Spy-DacX & FNAMITAKRG & -KTRLITIVM & GVGDWSDQNG & EFYRHPFVNA & ITEKGE . . K & DSKTLSKKAR & & . .LVPQTKKE & TSSKQQHFKA & TKKQSY & 363 \\
\hline Sau-DacX & YNHTITTKRG & . KFRINQVIM & GAGDYKNLGG & EKQRNMMGNA & $\begin{array}{c}\text { LMERSEDOYX } \\
\text { 證 }\end{array}$ & YVKILSKGEQ & RINGKKYYVE & NDLYDVLPSD & FSKKDYKLVV & EDGKVH & \\
\hline SU-DacA & CFTGTAERN & . GMRVITVVL & NAKG . . . NL & HTGRFDETKK & MFDYAFDNFS & MKEIYAEGDQ & VKGHKTISVD & KGKEKEVGIV & TNKAESLPVK & NGEEKN & $357 / 443$ \\
\hline 3st-DacA & CETGTAKRN & . GVRLISVVM & NAKDASGKTT & KEARFKETEK & LFNYGFNQYS & LETLYPKGYQ & LKGKETLPVV & KGKEKEVRVA & TGKNLDLLVK & NGEEKQ & \\
\hline Spy-DacA & SFVATSVEN & - QMRVITVVL & NADQ . . SHED & DLAIFKTTNQ & LLQYLLINFQ & KVQLIENNKP & V...KTLYVL & DSPEKNCQTC & SPK. . . . . & & 324 \\
\hline Spn-DacA & SFVGTTVEK & - GMRVITVVL & NADH . . QDNN & PYARFTATSS & LMDYISSTFT & LRKIVQQGDA & YQD. SKAPVQ & DGKEDTVIAV & DIYLIER & VGNQSS & \\
\hline Spy-DacA* & CLVVTSIEN & . GMRLITVIL & NADG . SDKN & QNTRFEQANR & LLDYVARTYC & RRKI LKKGSL & VSE.RSLPIQ & DGQVKELPIS & TIILQ & QGEQVP & \\
\hline Eco-DacC & YNLVASATQG & . DMRLISVVL & GAK...... T & DRIRFNESEK & LLTWGERFEE & TVTPIKPDAT & F. . VTQRVW & FGDKSEVNLG & AGEAGSVTIP & RGQLKN & 00 \\
\hline Eco-DacA & YNLVASATEG & - QMRLISAVM & GGR. . . . T & FKGREAESKK & LLTWGFRFEE & GKE & F...AS & FGDSDRASLG & LTIP & RGRMKD & \\
\hline $\mathrm{CA}$ & NLVASATTS & NNMRLISVVM & GNR.....T & YKGREVESKK & LLQWGEANEE & TEKTLEAGKE & I . . SEQRVY & VKLG & ITIP & KGKQSE & \\
\hline DacD & FNLIASAVDG & - QRRLIAVVM & GAD.....S & AKGREEEARK & LLRWGQQNFT & RGKK & V...GTERIW & YGDKENIDLG & TEQEFWMVLP & KAEIPH & \\
\hline su-Dack & YCLTASAKKG & - NMRAIAVVF & GAS. . . . T & PKERNAQVTK & AFSQYE & RNQT & V. . AKI & KGKQKFIELT & TSEPISILTK & KGEDMN & \\
\hline $\mathrm{acF}$ & TEVGAAARG & . GRRLVIAMM & YGLVKEGGPT & Y...WDQAAT & LEDWGEA. . . & QA.. & $\ldots$...sv & & & & \\
\hline Bsu-DacF* & RTLVSTASKD & .GIDLIA... & $\ldots$ VTINDPN & D...W & MFNYVEEHYQ & YLIAKKG. . & & KGTE & YLLT & EEKEN & \\
\hline de & CLVM. . RTT & & & & W....LE & & & & & & \\
\hline bpg & CLVM. . RTV & INNKPVALVV & ....MDAFG & KYTHFADASR & LRTW. . . . IE & VPAA & ALSYKKOKAA & QMAAAGQTAQ & & & 313 \\
\hline$c h-P b p G$ & HCLVM. . RTQ & MGRRQVAFVV & . . . LLTKG & KLSPVC & LRTW . . . IE & SE & . & $\cdots$ & $\cdots$ & $\cdots \cdots$ & \\
\hline in-PbpG & YNLVFINKHR & CKNATIGVIS & $\ldots \ldots$ IN. & ....nNTSSA & YRSS . . . FT & KSKLEKFGCT & ALNGRT IRDV & AGEAQYEDGY & DEVGFNTLIQ & KLSK. . & $292 / 292$ \\
\hline & VLAGFMTNA & & & & LYNELY & & & & & & \\
\hline Co-DacB & YNQAGEITTA & GQRMAFVQY & LSGYAVEPAD & QRNRRI PLVR & EESRLYKDIY & & & & & & \\
\hline DacB & SALSGYVPGP & EG.ELAFSIV & NNGH.SGPAP & L. AVQDAIAV & RLAEYAGHQA & PEGARMMRGP & VQGSGELECS & ant & & & \\
\hline & SLSGYAETK & KKLVFS IL & LNGLIDEEDG & K.DIEDQIAV & che & & $\ldots \ldots \ldots$ & & & & $491 / 491$ \\
\hline sp-DacB & SLTGYVENQ & VGTVAFSFM & VNNSDLGASV & REAMKQMVL & AQVEKCQP & & & & & & \\
\hline b-DacB & NSLVGVLTDR & TFAFI & SNEAGPNGRN & MDALATKLW & GСTT.... & & & & & & \\
\hline & ALAGYWLGD & KPMAVV.VII & NSGRAVSLLP & ¿DNFVAKNI & & & & & & & \\
\hline sp-DacB* & SALAGT I PTQ & ERGTVWFAII & NNGPNFDRLR & VEQDRLLQQI & AEHWQVLPEN & LNAGPMDKVL & LGDPARNLTP & PRSES..... & & & $430 / 430$ \\
\hline
\end{tabular}

Fig. 4. Multiple alignment of low-molecular-mass PBPs. The alignment was generated using the PILEUP program of the GCG package (Genetics Computer Group, 1995). The dendrogram generated is shown at the upper left. The five $E$. coli paralogues are shown in bold type. Immediately to the right of the dendrogram are our individual PBP designations, accession or contig numbers (with original designations in parentheses), last residue number of signal peptide prior to cleavage $(\downarrow)$ and beginning residue number shown in the multiple alignment. At the far lower right is given the number of the final residue presented followed (slash) by the number of the final sequence residue. Residues that are highly conserved within any one of the four clusters compared are printed in bold type. Solid bars join residues that are highly conserved between a given pair of groups. Grey bars indicate less highly conserved residue groupings. Asterisks mark anchor residues conserved throughout the entire family of low-molecular-mass PBPs. (Lower-case letters within the SxN and KTG motifs of PBPs from Vch-PbpG and Spy-DacA, respectively, are probably errors which can be expected because of the preliminary status of these genome sequencing projects.) A serine residue just prior to the $\mathrm{SxN}$ motif (corresponding to $P$. aeruginosa PbpG $S_{111}$ ) is conserved in each of the subgroups, but imperfectly aligned. The possibility that these serine residues are functionally equivalent is indicated by the double-bent lines between subgroups. The vertically divergent arrow shown within the DacB cluster indicates the region which was manually deleted to optimize the alignment as carried out by Mottl et al. (1991). The probable target sites for artifactual cleavage of $E$. coli and $P$. aeruginosa PBP7 (PpbG) proteins by OmpT to produce PBP8 species are double-underlined. Organism abbreviations: Spy, Streptococcus pyogenes; Sau, Staphylococcus aureus; Bsu, Bacillus subtilis; Bst, B. stearothermophilus; Spn, Streptococcus pneumoniae; Eco, Escherichia coli; Hin, Haemophilus influenzae; Mtb, Mycobacterium tuberculosis; Pae, Pseudomonas aeruginosa; Vch, Vibrio cholerae; Act, Actinomadura sp.; Ssp, Synechocystis sp.; Ngo, Neisseria gonorrhoeae.

member of the DacB cluster. Unlike E. coli, B. subtilis apparently lacks a PbpG homologue. The completely sequenced genome of $H$. influenzae reveals a similar partitioning of paralogues into the three groups as found in $E$. coli, but only a single paralogue represents the DacA-F group. The much more distant cyanobacterium Synechocystis sp. expresses only two paralogues of the low-molecular-mass PBPs, these being divergent members of the DacB cluster.

The extent to which the major groupings shown in Fig. 4 correspond to functionally specialized PBPs is currently incompletely known. The data available indicate that cluster DacA-F contains DD-carboxypeptidases, whereas cluster PbpG contains DD-endopeptidases. Within the DacB grouping, E. coli DacB is a DDendopeptidase which has weak DD-carboxypeptidase activity. In view of the wide divergence within this group, different functional specialization within this group would not be surprising. For example, Synechocystis sp. DacB and $\mathrm{DacB}^{*}$ are logical candidates for functional divergence, as Synechocystis sp. DacB* has diverged more from its DacB paralogue than have the functionally different E. coli $\mathrm{DacA}$ and $\mathrm{PbpG}$ paralogues.

Thus far, PbpG homologues in different organisms (orthologues) are restricted to a relatively closely related group of organisms: E. coli, Vibrio cholerae, $P$. aeruginosa and $H$. influenzae. We could not identify $\mathrm{PbpG}$ orthologues in the nearly completed sequences of Neisseria gonorrboeae, Staphylococcus aureus or Streptococcus pyogenes. Perhaps the DacX group represented by the latter two organisms (Fig. 4) corresponds to another functionally specialized DD-endopeptidase cluster. DD-Endopeptidase function is also known to exist in E. coli for MepA, a non-homologue of PBPs. In E. coli the DD-endopeptidase activity appears to be due to redundant catalytic activities of $\mathrm{DacB}$ and PbpG, while DD-carboxypeptidase activity appears to be due to the redundant catalytic activities of $E$. coli DacA, DacC and DacD. In E. coli PbpG has been shown to constitute up to $30 \%$ of the total penicillin-binding proteins (Dougherty et al., 1996). 


\section{Signature amino acid motifs}

Members of the superfamily of serine-active-site penicillin-interacting proteins which includes the PBPs and $\beta$-lactamases share three major motifs: $S x x K$, $S / Y x N$ and $K / H T / S G$. At the family level within the superfamily, one can expect expanded motif signatures built around the invariant anchor residues. In the lowmolecular-mass PBP family the first motif is ${ }^{69} \mathrm{AS} x \times K x x \mathrm{~T}^{77}$ (superfamily anchor residues are in bold; residue numbers are according to the E. coli $\mathrm{PbpG}$ sequence), as seen in Fig. 4. At lower hierarchical clustering levels, an expanded signature may typify a given cluster. For example, the signature for the DacB cluster is ASxxKxxTxxAA.

The second motif is ${ }^{127} \mathrm{~S} \times \mathrm{N}(\mathrm{x})_{35} \mathrm{G}^{165}$. If the DacB group is excluded, the remaining three clusters share the signature motif ${ }^{127} \mathrm{SxNxA}(\mathrm{x})_{4} \mathrm{~A}(\mathrm{x})_{9} \mathrm{~F}(\mathrm{x})_{3} \mathrm{M}(\mathrm{x})_{7} \mathrm{G}(\mathrm{x})_{10}$ $\mathrm{G}^{165}$. Just prior to the $\mathrm{SxN}$ motif is a conserved serine residue ${ }^{1{ }^{15} \mathrm{~S}}$ in E. coli $\left.\mathrm{PbpG}\right)$ which although imperfectly aligned between groups may be functionally equivalent.

The third major signature motif for low-molecular-mass PBPs is ${ }^{234} \mathrm{KTGS} / \mathrm{T}^{237}$. A fourth motif is a peptide segment having one or two dicarboxylic acids between the SxN and KTG motifs. Henderson et al. (1995) speculated that residue ${ }^{180} \mathrm{D}$ might serve this function in E. coli PbpG. Fig. 4 shows this and surrounding residues to be indeed highly conserved in all clusters except the $\mathrm{DacB}$ cluster. The motif is ${ }^{177} \mathrm{~S} / \mathrm{TAxD}^{180}$.

\section{ACKNOWLEDGEMENTS}

The authors thank the Institute for Genomic Research, the Gonococcal Genome Sequencing Project (University of Oklahoma), and the Streptococcus Sequencing Project (University of Oklahoma) for availability of sequence data prior to publication. They appreciate the advice and help of Genshi Zhao. This publication is Florida Agriculture Experiment Station Journal Series no. R-05939.

\section{REFERENCES}

Baquero, M.-R., Bouzon, M., Quintela, J. C., Ayala, J. A. \& Moreno, F. (1996). dacD, an Escherichia coli gene encoding a novel penicillin-binding protein (PBP6b) with DD-carboxypeptidase activity. J Bacteriol 178, 7106-7111.

Bradford, M. M. (1976). A rapid and sensitive method for the quantitation of microgram quantities of protein utilizing the principle of protein-dye binding. Anal Biochem 72, 248-254.

Chang, A. C. Y. \& Cohen, S. N. (1978). Construction and characterization of amplifiable multicopy DNA cloning vehicles derived from the p15A cryptic miniplasmid. J Bacteriol 134, 1141-1156.

Defeyter, R., Kado, C. I. \& Gabriel, D. W. (1990). Small, stable shuttle vectors for use in Xanthomonas. Gene 88, 65-72.

Dougherty, T. J., Kennedy, K., Kessler, R. E. \& Pucci, M. J. (1996). Direct quantitation of the number of individual penicillin-binding proteins per cell in Escherichia coli. J Bacteriol 178, 6110-6115. Genetics Computer Group (1995). Wisconsin sequence analysis package, version 8.0. Madison, WI: Genetics Computer Group.
Ghuysen, J.-M. (1991). Serine $\beta$-lactamases and penicillin binding proteins. Annu Rev Microbiol 45, 37-67.

Ghuysen, J.-M. \& Dive, G. (1994). Biochemistry of the penicilloyl serine transferases. In Bacterial Cell Wall, pp. 103-129. Edited by J.-M. Ghuysen \& R. Hekenbeck. Amsterdam: Elsevier.

Gupta, S. D., Lee, B. T., Camakaris, J. \& Wu, H. C. (1995). Identification of $c u t C$ and $c u t F(n p l E)$ genes involved in copper tolerance in Escherichia coli. J Bacteriol 177, 4207-4215.

Henderson, T. A., Dombrosky, P. M. \& Young, K. D. (1994). Artifactual processing of penicillin-binding proteins 7 and $1 \mathrm{~b}$ by the OmpT protease of Escherichia coli.J Bacteriol 176, 256-259.

Henderson, T. A., Templin, M. \& Young, K. D. (1995). Identification and cloning of the gene encoding penicillin-binding protein 7 of Escherichia coli. J Bacteriol 177, 2074-2079.

Henderson, T. A., Young, K. D., Denome, S. A. \& Elf, P. K. (1997). $\mathrm{AmpC}$ and $\mathrm{AmpH}$, proteins related to the class $\mathrm{C} \beta$-lactamases, bind penicillin and contribute to the normal morphology of Escherichia coli. J Bacteriol 179, 6112-6121.

Kamoun, S., Kamdar, H. V., Tola, E. \& Kado, C. I. (1992). Incompatible interactions between crucifers and Xanthomonas campestris involve a vascular hypersensitive response: role of the brpX locus. Mol Plant-Microbe Interact 5, 22-23.

Liao, X. \& Hancock, R. E. W. (1995). Cloning and characterization of the Pseudomonas aeruginosa $p b p B$ gene encoding penicillinbinding protein 3. Antimicrob Agents Chemother 39, 1871-1874.

Liao, X. \& Hancock, R. E. W. (1997). Identification of a penicillinbinding protein 3 homolog, $\mathrm{PBP} 3 \mathrm{x}$, in Pseudomonas aeruginosa: gene cloning and growth phase-dependent expression. J Bacteriol $179,1490-1496$.

Malouin, F., Chamberland, S., Brouchu, N. \& Parr, J., Jr (1991). Influence of growth media on Escherichia coli cell composition and ceftazidime susceptibility. Antimicrob Agents Chemother 35, 477-483.

Mottl, H., Terpstra, P. \& Keck, W. (1991). Penicillin-binding protein 4 of Escherichia coli shows a novel type of primary structure among penicillin-interacting proteins. FEMS Microbiol Lett 78, 213-220.

Murray, T., Popham, D. L. \& Setlow, P. (1997). Identification and characterization of $p b p A$ encoding Bacillus subtilis penicillinbinding protein 2A. J Bacteriol 179, 3021-3029.

Nakai, K. \& Kanehisa, M. (1991). Expert system for predicting protein localization sites in Gram-negative bacteria. Proteins Struct Funct Genet 11, 95-110.

Neu, H. C. \& Chou, J. (1967). Release of surface enzymes in Enterobacteriaceae by osmotic shock. J Bacteriol 94, 1934-1945.

Noguchi, H., Matsuhashi, M. \& Mitsuhashi, S. (1979). Comparative studies of penicillin-binding proteins in Pseudomonas aeruginosa and Escherichia coli. Eur J Biochem 100, 41-49.

Parales, R. E. \& Harwood, C. S. (1992). Characterization of the genes encoding $\beta$-ketoadipate: succinyl-Coenzyme A transferase in Pseudomonas putida. J Bacteriol 174, 4657-4666.

Romeis, T. \& Höltje, J.-V. (1994). Penicillin-binding protein $7 / 8$ of Escherichia coli is a DD-endopeptidase. Eur $J$ Biochem 224, $597-604$.

Sambrook, J., Fritsch, E. F. \& Maniatis, T. (1989). Molecular Cloning: a Laboratory Manual 2nd edn. Cold Spring Harbor, NY: Cold Spring Harbor Laboratory.

Simon, R., Priefer, U. \& Puhler, A. (1983). A broad host range mobilization system for in vivo genetic engineering: transposon mutagenesis in gram negative bacteria. Bio/Technology 1, 784-791. 
Song, J. \& Jensen, R. A. (1996). PhhR, a divergently transcribed activator of the phenylalanine hydroxylase gene cluster of Pseudomonas aeruginosa. Mol Microbiol 22, 497-507.

Tuomanen, E. \& Schwartz, J. (1987). Penicillin-binding protein 7 and its relationship to lysis of nongrowing Escherichia coli. $J$ Bacteriol 169, 4912-4915.

Van Heijenoort, J. (1996). Murein synthesis. In Escherichia coli and Salmonella: Cellular and Molecular Biology, 2nd edn. pp. 1025-1034. Edited by F. C. Neidhardt and others. Washington, DC: American Society for Microbiology.

Waxman, D. J. \& Strominger, J. L. (1983). Penicillin-binding proteins and the mechanism of action of beta-lactam antibiotics. Annu Rev Biochem 52, 825-869.
Yanisch-Perron, C., Vieira, J. \& Messing, J. (1985). Improved M13 phage cloning vectors and host strains: nucleotide sequences of the M13mp18 and pUC vectors. Gene 33, 103-119.

Zhao, G., Xia, T., Aldrich, H. \& Jensen, R. A. (1993). Cyclohexadienyl dehydratase from Pseudomonas aeruginosa is a periplasmic protein. J Gen Microbiol 139, 807-813.

Zhao, G., Xia, T., Song, J. \& Jensen, R. A. (1994). Pseudomonas aeruginosa possesses homologues of mammalian phenylalanine hydroxylase and 4a-carbinolamine dehydratase/DCoH as part of a three-component gene cluster. Proc Natl Acad Sci USA 91, $1366-1370$.

Received 10 October 1997; accepted 27 November 1997. 